\title{
Potential impacts of stratospheric aerosol injection on drought risk managements over major river basins in Africa
}

\author{
Babatunde J. Abiodun ${ }^{1}$ (D) Romaric C. Odoulami ${ }^{2}$ (D) - Windmanagda Sawadogo ${ }^{3}$ (D) \\ Olumuyiwa A. Oloniyo ${ }^{1}$. Abayomi A. Abatan ${ }^{4}$ - Mark New ${ }^{2}$. Christopher Lennard ${ }^{1}$. \\ Pinto Izidine $^{1} \cdot$ Temitope S. Egbebiyi $^{1}$ - Douglas G. MacMartin ${ }^{5}$
}

Received: 12 June 2021 / Accepted: 10 November 2021/Published online: 15 December 2021

(c) The Author(s) 2021

\begin{abstract}
Most socio-economic activities in Africa depend on the continent's river basins, but effectively managing drought risks over the basins in response to climate change remains a big challenge. While studies have shown that the stratospheric aerosol injection (SAI) intervention could mitigate temperature-related climate change impacts over Africa, there is a dearth of information on how the SAI intervention could influence drought characteristics and drought risk managements over the river basins. The present study thus examines the potential impacts of climate change and the SAI intervention on droughts and drought management over the major river basins in Africa. Multi-ensemble climate simulation datasets from the Stratospheric Aerosol Geoengineering Large Ensemble (GLENS) Project were analysed for the study. The Standardized Precipitation Evapotranspiration Index (SPEI) and the Standardized Precipitation Index (SPI) were used to characterize the upper and lower limits of future drought severity, respectively, over the basins. The SPEI is a function of rainfall and potential evapotranspiration, whereas the SPI is only a function of rainfall, so the difference between the two indices is influenced by atmospheric evaporative demand. The results of the study show that, while the SAI intervention, as simulated in GLENS, may offset the impacts of climate change on temperature and atmospheric evaporative demand, the level of SAI that compensates for temperature change would overcompensate for the impacts on precipitation and therefore impose a climate water balance deficit in the tropics. SAI would narrow the gaps between SPEI and SPI projections over the basins by reducing SPEI drought frequency through reduced temperature and atmospheric evaporative demand while increasing SPI drought frequency through reduced rainfall. The narrowing of this gap lowers the level of uncertainty regarding future changes in drought frequency, but nonetheless has implications for future drought management in the basins, because while SAI lowers the upper limit of the future drought stress, it also raises the lower limit of the drought stress.
\end{abstract}

Keywords Climate change $\cdot$ Geoengineering $\cdot$ Droughts $\cdot$ African river basin

Babatunde J. Abiodun

babiodun@csag.uct.ac.za

Extended author information available on the last page of the article 


\section{Introduction}

Drought poses a significant threat in Africa, especially over the river basins, where it usually stresses water resources and disrupts the socio-economic activities of the riparian countries. For instance, in 1972-1974, severe droughts devastated the economies of many countries in West Africa (Derrick 1977), and in 1984-1985, a megadrought killed about 450,000 people in Ethiopia (Guha-Sapir et al. 2004). The southern African drought of the 1990s affected most river basins and countries in the region. This drought destroyed crops in the Limpopo River basin, induced a water shortage that affected millions of people in the basin's riparian countries (i.e. Malawi, Zimbabwe, Lesotho, and South Africa), and disrupted socio-economic activities in these countries (Clay et al. 1995; Calow et al. 2010). More recently, a severe drought that affected the Berg and Overberg catchments of the Western Cape in South Africa drastically reduced the dam water level in Cape Town (Africa's most attractive tourist city), leading to water restrictions for the millions of people in the city (Wolski 2018; Sousa et al. 2018; Mahlalela et al. 2019; Omar and Abiodun 2020; Odoulami et al. 2021). Several studies have reported an increasing trend in drought characteristics (severity, frequency, and persistence) over the last decades (Masih et al. 2014; Omar and Abiodun 2020; Spinoni et al. 2019; Padrón et al. 2020) and attributed this trend to global warming (e.g. Uhe et al. 2017; Funk et al. 2018; Bellprat et al. 2015; Pascale et al. 2020; Otto et al. 2018). These trends may well continue into the future (Cook et al. 2020; Spinoni et al. 2020; Abiodun et al. 2019).

The potential impacts of global warming on droughts and socio-economic activities in Africa have been discussed by several studies (e.g. Joshi et al. 2011; James and Washington 2013; Trenberth et al. 2014). Some of these studies indicated that, although Africa has a low level of greenhouse gas (GHG) emissions, the continent would experience the worst impacts of anthropogenic warming because so many African countries are poor or ravaged by war already (e.g. Hope 2009; Verissimo 2020). Such warming would add extra heat into the atmosphere, and most of this heat would go into drying the continent (Feddema 1999; Lian et al. 2021; Onyutha 2021). Hence, the warming would amplify the evaporative demand of the atmosphere, thus triggering natural droughts more quickly and making such droughts more intense and longer-lasting. East Africa and much of tropical Africa are projected to become generally wetter, but the southern African region (particularly South Africa) is projected to become generally drier under global warming, with an associated increase in dry spells and droughts (Maúre et al. 2018; Abiodun et al. 2019; Dosio et al. 2019; Cook et al. 2020). Abiodun et al. (2018) projected an increase in drought intensity and frequency over the major river basins in southern Africa at various global warming levels. Every bit of additional warming would pose even greater risks for Africa in the form of more potential crop failures because the greater evaporation from the warming would reduce soil moisture (Serdeczny et al. 2017; Shiferaw et al. 2014). This would negatively impact water availability for both crops and pastures, with a greater chance of failed harvests and reduced livestock feeds. In addition, adequate provision of water for livestock production could become more difficult under climate change. For example, Masike and Urich (2009) estimated that the cost of supplying livestock water from boreholes in Botswana could increase by $23 \%$ by 2050 due to increased hours of groundwater pumping needed to meet livestock water demands under warmer and drier conditions. The impacts of climate change on droughts could furthermore heighten conflicts between crop farmers 
and cattle herders in the Sahel region. Hence, there is a need to mitigate the impacts of global warming on droughts and various socio-economic activities in Africa.

Solar radiation management (SRM or solar geoengineering) has been proposed as a quick and relatively cheap option to mitigate climate change impacts (Robock 2015; Kravitz et al. 2016). SRM aims to counteract GHG-driven global warming by artificially reflecting a small amount of inbound sunlight out into space. One of the most prominent SRM approaches is stratospheric aerosol injection (SAI), which involves the injection of gaseous aerosol precursors like sulphur dioxide into the tropical stratosphere to block a small amount of incoming solar radiation from reaching the earth's surface and thus to reduce the warming level around the earth's surface (Robock 2015). Although SAI has not yet been implemented, the temporary global cooling experienced after major volcanic eruptions (e.g. Mount Pinatubo in the Philippines in 1991 and El Chichón in Mexico in 1982) that released large amounts of sulphate aerosols into the stratosphere is evidence of the cooling potential of SAI (Stenchikov et al. 1998; Hegerl et al. 2003; Proctor et al. 2018). However, just like every geoengineering approach, the deployment of SAI requires a prior fair and equitable evaluation of its potential to influence various components of the climate system (NAS 2021). Although research relating to SAI is still in its infancy stages, the approach is controversial because its full effects on different components of the earth's systems are unknown. There are also concerns about who will make the decision to implement SAI. Previous studies stated that, while SAI could reduce the global temperature, it would not restore the world's climate to pre-global warming levels. It would also lead to additional changes in regional precipitation (Caldeira and Wood 2008; Ricke et al. 2010; Jones et al. 2010). For example, Simpson et al. (2019) and Cheng et al. (2019) showed that SAI could reduce precipitation (relative to the pre-global warming world) in most parts of the world, including over the Indian summer monsoon region, most parts of Africa, Southern America, and the Mediterranean region (wintertime only). Although some of these studies have confirmed the effectiveness of SAI in reducing temperatures in Africa (Pinto et al. 2020; Da-Allada et al. 2020), there is a dearth of information on the potential impacts of SAI on future droughts in Africa. While Odoulami et al. (2021) showed that SAI could reduce the risk of a severe drought in Cape Town in the future, their study used only rainfall deficit as a proxy for drought and focused only on a local scale event, making the findings location specific. Hence, there is a need to improve knowledge on the potential impacts of SAI on drought over Africa more generally, using appropriate drought indices to characterize droughts.

This study thus investigates the impacts of SAI on droughts over Africa with a focus on major river basins. The study uses two indices to identify droughts and quantify the potential impacts of SAI on the severity, frequency, and duration of such droughts. Section 2 of the paper describes the methodology, while Section 3 presents and discusses the results, and Section 4 provides the concluding remarks.

\section{Methodology}

\subsection{Study domain}

Our study domain is Africa but with a focus on 12 major river basins in the continent. The locations of these basins are shown in Fig. 1, while some information about the basins is presented in Table 1. These basins have been selected because they are the biggest and 


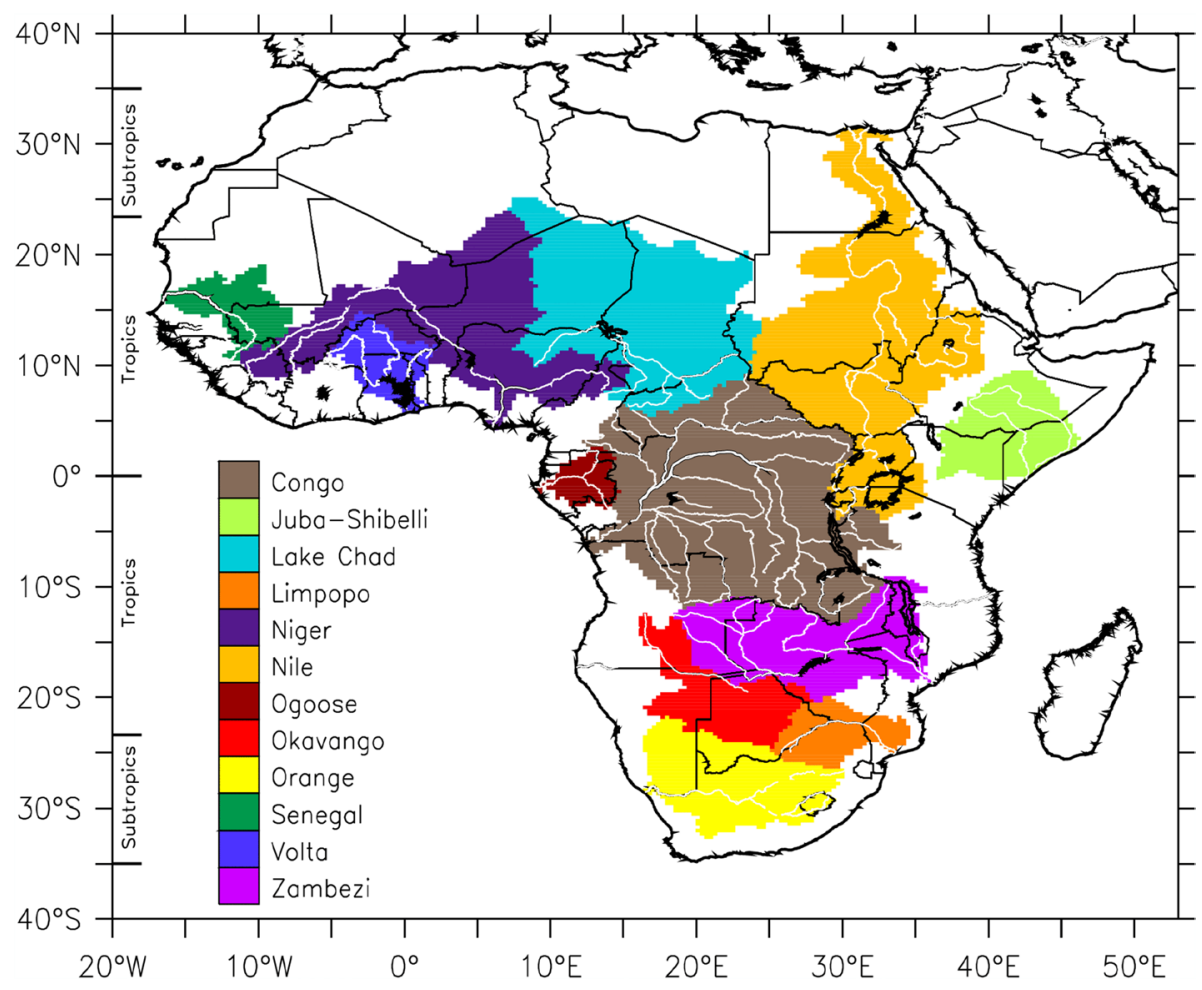

Fig. 1 The study domain, showing the locations of the 12 major river basins (shaded) used in the study. The white lines on the basins show the rivers. The zones delineated as tropics $\left(23.4^{\circ} \mathrm{N}-23.4 \mathrm{~S}\right)$ and subtropics $\left(23.4^{\circ} \mathrm{S}-35^{\circ} \mathrm{S}\right.$ and $\left.23.3^{\circ} \mathrm{S}-35.0^{\circ} \mathrm{N}\right)$ in the study are indicated

most transboundary basins in Africa and are good representatives of other river basins over the continent. The sizes of the basins range from 223,400 $\mathrm{km}^{2}$ (Ogoose basin) to 3,699,100 $\mathrm{km}^{2}$ (Congo basin), while the numbers of the riparian countries vary from 3 (Juba-Shibelli basin) to 11 (Nile basin), and the populations of basin inhabitants range from 800,000 people (Okavango) to $280,000,000$ people (Nile). These twelve basins, which drive various socio-economic activities (such as agriculture, mining, power generation, and industry) in their riparian countries, play important roles in sustainable developments in Africa (ARBO 2007). For example, the Zambezi and the Limpopo attract tourists from around the world to see the majestic Victoria Falls and the Big Five in the Kruger National Park. Lake Chad basin supports the livelihood of the local community through the provision of water for agriculture, fishing, and pasture. The Nile basin provides irrigation for more than 5.5 million ha with the potential to expand to 10.4 million ha. The Niger basin currently supports 7,000 GWH hydropower and has the potential for 30,000 GWH. However, drought continues to fuel desertification, land degradation, poverty, and conflicts in these basins.

\subsection{Data}

The climate simulation datasets from the Stratospheric Aerosol Geoengineering Large Ensemble (GLENS) Project dataset (Tilmes et al. 2018) were analysed for the study. The 


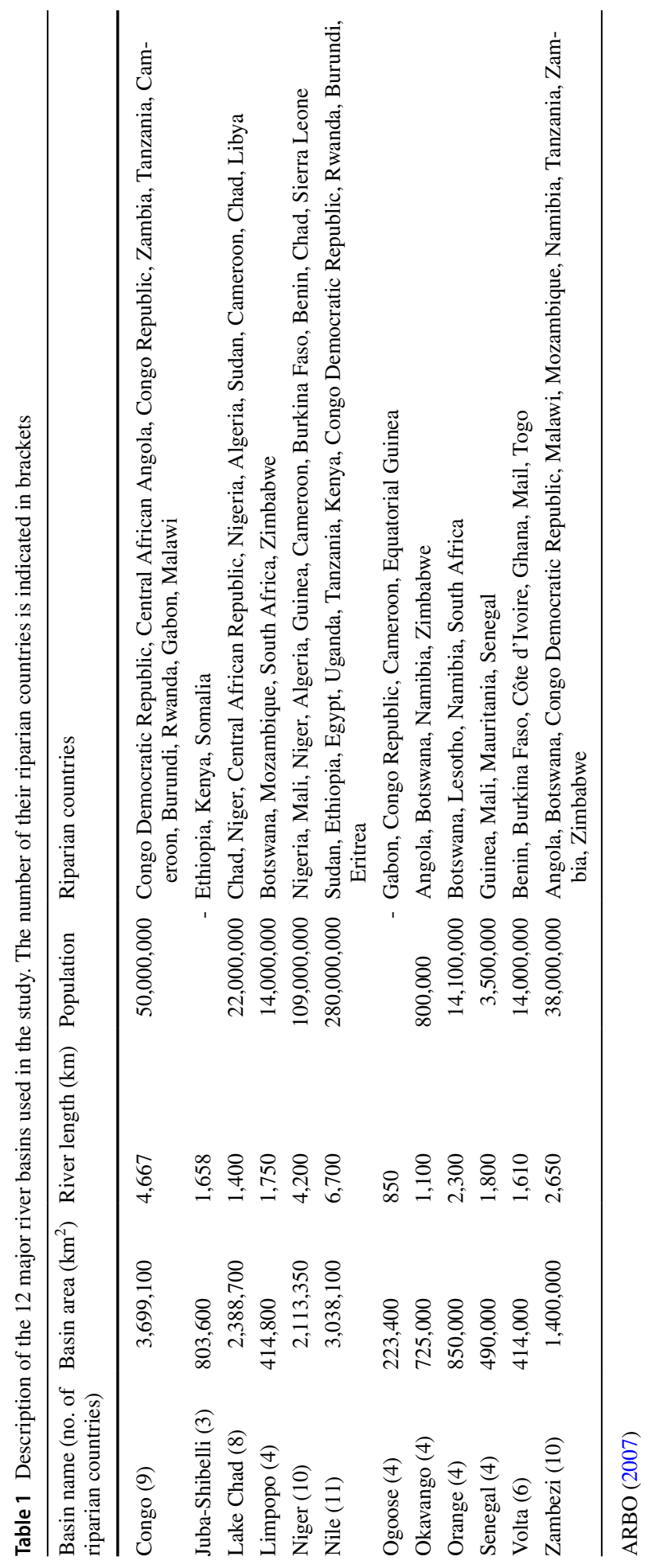


GLENS datasets were generated with the Community Earth System Model (CESM1), which uses the Whole Atmosphere Community Climate Model (WACCM) as its atmospheric component (Mills et al. 2017). The CESM1 model data has a horizontal resolution of $0.9^{\circ}$ latitude $\times 1.25^{\circ}$ longitude with 70 vertical levels from the surface up to $140 \mathrm{~km}$ (Tilmes et al. 2018). We used two experiments from the GLENS project dataset, namely, control and feedback experiments. In both experiments, the simulations were forced with a high GHG emission scenario (RCP8.5), but in the feedback experiment, sulphur dioxide was injected into the tropical stratosphere at four latitudes (i.e. $15^{\circ} \mathrm{S}, 15^{\circ} \mathrm{N}, 30^{\circ} \mathrm{S}$, and $30^{\circ}$ $\mathrm{N})$ along $180^{\circ} \mathrm{E}$ at roughly $6-7 \mathrm{~km}$ above the tropopause (Tilmes et al. 2018). The sulphate injection is intended to maintain the global mean temperature as well as the inter-hemispheric and equator-to-pole near-surface temperatures at the 2020 level until the end of the century while keeping other forcing as in the RCP8.5 scenario. The control experment has two datasets: baseline simulation dataset (2010-2030) and RCP8.5 simulation datasets $(2020-2100)$. The feedback experiment has one dataset, called feedback simulation dataset (2020 - 2100). However, while the control baseline simulation dataset (2010-2030) and feedback simulation dataset) have twenty simulation ensemble members each, the control RCP8.5 simulation dataset) has only three simulation ensemble members. To address this problem, we generated twenty ensemble members for the RCP8.5 simulation dataset by duplicating the original three ensemble members. That is, in the twenty-member ensemble, ensemble members 1, 4, 7, 10,13,16, and 19 are duplicates, ensemble members $2,5,8,11,14,17$, and 20 are duplicates, and ensemble members $3,6,9,13,15$, and 18 are duplicates. With this, the number of ensemble members in the RCP8.5 simulation dataset 1 matches that of other two datasets. The justification for this approach is that the climate simulations are all statistically independent. The approach frees us from limiting the analysis to only three ensemble members (which would be too few for calculating changes in drought characteristics) or from working with unequal numbers of ensemble members. Pinto et al. (2020) has evaluated the historical simulations of model used in the GLENS, found that the model gives credible simulation of African climate, and shown that the model's perfomance compares well with other CMIP5 models.

Twenty years simulation data were analysed in each dataset. The control baseline simulation dataset was used to study the characteristics of the present-day climate (2011-2030; hereafter, PRS), the control RCP8.5 simulation dataset was used to study the characteristics of the future climate under the RCP8.5 scenario (2071-2090; hereafter RCP8.5) while the feedback simulation dataset was used to examine the characteristics of the future climate under the RCP8.5 scenario with the SAI intervention (2071-2090; hereafter, SAI). We chose the period of 2011-2030 as the present-day (or baseline) climate because this period had been used to define the targets for SAI to keep the surface temperature at the 2020 level until the end of the century under the RCP8.5 scenario (Tilmes et al. 2018; Simpson et al. 2019). Hence, RCP8.5 minus PRS quantifies the impacts of the RCP8.5 scenario on the future climate, SAI minus PRS shows the combined impacts of RCP8.5 and the SAI intervention on the future climate, and SAI minus RCP8.5 shows the impacts of SAI on the future climate.

\subsection{Methods}

We used two drought indices to characterize droughts in this study, namely, the Standardized Precipitation Index (SPI; McKee et al. 1993) and the Standardized Precipitation 
Evapotranspiration Index (SPEI; Vicente-Serrano et al. 2010a, b). Although there are numerous drought indices (Svoboda and Fuchs 2016), the most used meteorological indices for water resource monitoring and management are the Palmer Drought Severity Index (PDSI; Palmer 1965), SPI, and SPEI. We chose SPEI and SPI for two reasons. Firstly, the SPEI and SPI calculations are much easier than the PDSI calculation. Secondly, SPEI and SPI are multiscale drought indexes while PDSI is not. As drought is a multiscale phenomenon, it is essential to employ multiscale drought indices for monitoring and managing droughts because these indices can use the timescale of accumulated water deficit to functionally separate different types of droughts (e.g. hydrological, environmental, agricultural, and other droughts) that influence water resources (Vicente-Serrano et al. 2015). For example, on short timescales ( $\leq 6$ months), the SPEI and SPI are closely related to soil moisture, while at longer timescales ( $\geq 9$ months), they are related to groundwater and reservoir storage (McKee et al. 1993; Beguería et al. 2014). Both indices (i.e. SPEI and SPI) have been used for drought identification, monitoring, and projections in Africa (e.g. Meque and Abiodun 2015, Oguntude et al. 2018; Nguvava et al. 2019; Gore et al. 2020), as well as elsewhere around the world (e.g. Beguería et al. 2014; Abatan et al. 2017, 2018). The SPI is the World Meteorological Organization (WMO) adopted drought index for all national meteorological and hydrological services worldwide (Hayes et al. 2011; WMO 2012). However, the SPI uses only precipitation data to characterize droughts, thereby assuming that the variability of precipitation is much higher than the variability of other variables (e.g. temperature, evapotranspiration, wind speed, and relative humidity) that influence droughts and that there are no trends in these other variables (Vicente-Serrano et al. 2015). Hence, SPI may not account for the influence of global temperature increase (i.e. global warming) on drought characteristics. To overcome this limitation, the SPEI was developed as an extension of SPI (Vicente-Serrano et al. 2010a).

The formulations of SPI and SPEI are similar, except that SPI is based on precipitation while SPEI is based on climate water balance (CWB), which is the difference between precipitation (P) and potential evapotranspiration (PET) (i.e. $\mathrm{CWB}=\mathrm{P}-\mathrm{PET}$ ). The SPEI may give a more reliable measure of drought severity than SPI because, by using CWB, SPEI characterizes droughts by comparing the available water (i.e. P) with the atmospheric evaporative demand (i.e. PET). The notion of using actual evapotranspiration (ET, instead of PET) in the calculation of CWB and SPEI was discussed by Beguería et al. (2014), who argued that doing so would contradict the idea behind SPEI. The idea behind SPEI is to obtain the highest drought stress possible, by comparing the highest possible evapotranspiration (i.e. atmospheric evaporative demand) with the currently available water (i.e. precipitation). In contrast, by neglecting evapotranspiration, the SPI provides the lowest drought stress possible. Hence, for any given atmospheric condition, SPEI can be used to quantify the upper bound of drought severity or stress while SPI can be used to depict the lower bound (Abiodun et al. 2019). In the present study, we used the gap between SPEI (upper bound) and SPI (lower bound) to examine the extent to which trends in PET could alter the characteristics of the future droughts.

We calculated the two drought indices by using the SPEI Package in the R software (https://cran.r-project.org/web/packages/SPEI/SPEI.pdf). The algorithm uses the same procedure for calculating both indices, except that it uses precipitation as input data for calculating SPI and CWB as input data for calculating SPEI. For SPI, the algorithm transforms the precipitation data to Gaussian (normal) equivalents, which it uses to compute the dimensionless SPI value. For SPEI, the algorithm fits the CWB data to a probability distribution to transform the original values to standardized units. For both indices, the standardized values are comparable in space and time and at drought timescales. A detailed 
description and equations for calculating SPI and SPEI can be obtained in McKee et al. (1993) and Beguería et al. (2014). The PET data (for calculating CWB) were obtained from the maximum and minimum temperature data using the Hargreaves method (Hargreaves and Samani 1985). Both drought indices were calculated at a 12-month timescale over the study domain and then averaged over the river basins (Fig. 1). The values of the indices range from negative values (with $<-2.0$ denoting drought conditions) to positive values (with $>2.0$ denoting wet conditions). The focus of this study is on droughts that fall into at least the moderate drought category (i.e. $\leq-1.0$ ), so we used a threshold of -1.0 to identify droughts in the 12-month SPEI and SPI datasets. Hence, for each drought index, a drought event occurs when the value of the 12-month drought index is less than or equal to the threshold $(-1.0)$ continuously for at least 3 months. Three drought characteristics (duration, severity, and frequency) were extracted from the SPEI and SPI datasets. The duration of a drought event is defined as the period (i.e. number of months) in which the value of the drought index is continuously $\leq-1.0$ for the drought event. The severity of a drought event is defined as the average of the absolute values of the drought index over the drought duration. The drought frequency for a climate period is defined as the number of drought events that occur during the 20-year long time slices. We analysed the drought characteristics (frequency, duration, and severity) for the present-day climate (PRS) and future climate (RCP8.5 and SAI) to examine the impacts of RCP8.5 and SAI on the drought characteristics in the future (2071-2090) climate.

\section{Results and discussion}

\subsection{Projected changes in mean climate variables over Africa}

The potential impacts of RCP8.5 on the mean climate variables in the period (2071-2090) vary across the African continent (Fig. 2; column 2). While the warming increases the mean surface temperature by more than $2{ }^{\circ} \mathrm{C}$ over the entire continent, the maximum increase (about $5{ }^{\circ} \mathrm{C}$ ) is projected over northern and southern Africa and the minimum increase (about $1{ }^{\circ} \mathrm{C}$ ) over eastern Africa (Fig. 2b). In response to such warming, the atmospheric evaporative demand (i.e. potential evapotranspiration, PET) is projected to increase over the entire continent, with the maximum increase (up to $20 \mathrm{~mm} \mathrm{month}^{-1}$ ) in the sub-tropics and the minimum increase in the tropics (Fig. 2f). In contrast to the PET projection, precipitation is projected to increase in the tropics (up to $40 \mathrm{~mm} \mathrm{month}^{-1}$ in eastern Africa) but to decrease in the sub-tropics with the maximum decrease (about $-10 \mathrm{~mm} \mathrm{month}^{-1}$ ) in Southern Africa (Fig. 2j). However, in most parts of the tropics, the magnitude of the precipitation increase is higher than the PET increase. Hence, a net surplus in climate water balance (i.e. positive CWB) is projected over tropical Africa, while a net deficit (i.e. negative CWB) is projected over rest of the continent; the maximum deficit (about $-40 \mathrm{~mm} \mathrm{month}{ }^{-1}$ ) occurs over Southern Africa (Fig. 2n). These projections agree with the results of previous studies, which projected that global warming would make the wet regions of Africa wetter and the dry regions drier (Liu and Allan 2013; Feng and Zhang 2015).

The SAI intervention reduces the impacts of RCP8.5 on the climate variables in some cases but enhances it in others (Fig. 2d, h, 1, and p). For instance, it induces cooling to reduce the surface temperature by about $2{ }^{\circ} \mathrm{C}$ in eastern Africa and by about $4{ }^{\circ} \mathrm{C}$ in the sub-tropics (Fig. 2d). With this, it effectively offsets the impacts of RCP8.5 warming and keeps the future temperature changes to within $\pm 0.5{ }^{\circ} \mathrm{C}$ everywhere over the continent 

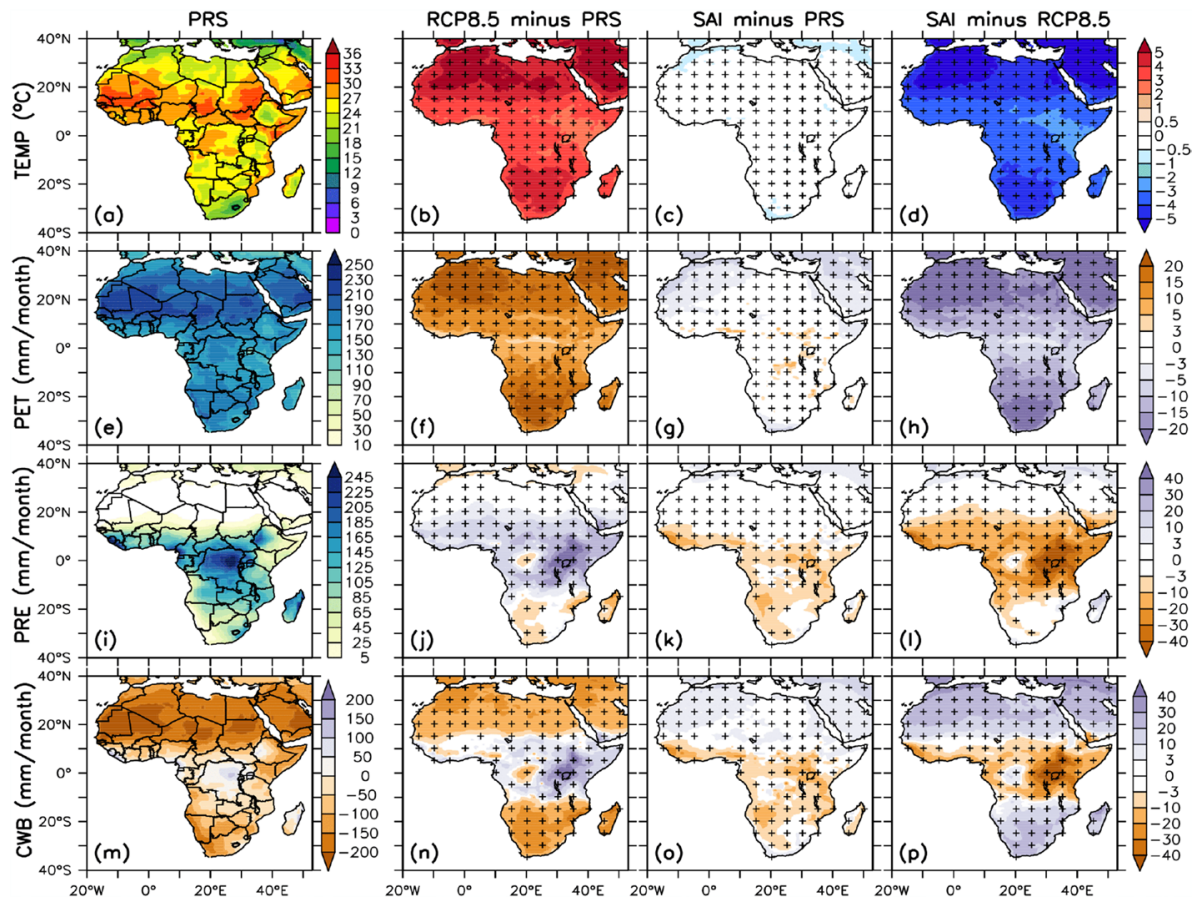

Fig. 2 The spatial distribution of climate variables (temperature [TEMP], potential evapotranspiration [PET], precipitation [PRE] and climate water balance [CWB]) over Africa in the present-day climate (PRS; 2011-2030) and their projected future changes in the period (2071-2090) under the RCP8.5 scenario without and with SAI (RCP8.5 minus PRS and SAI minus PRS, respectively). The extent to which the SAI influences the impacts of global warming on the variables is presented (SAI minus RCP8.5). Brown colour indicates dry tendency, while purple colour indicates wet tendency. The cross sign (+) indicates where at least $75 \%$ of the simulations agree on the sign of the changes

(Fig. 2c). It also offsets the increased PET (due to the RCP8.5 warming), with a less than $5 \mathrm{~mm}$ month $^{-1}$ decrease in the tropics and a more than $20 \mathrm{~mm}$ month $^{-1}$ decrease in the sub-tropics relative to RCP8.5 (Fig. 2h). This in turn keeps the change in atmospheric water demand to within $\pm 5 \mathrm{~mm} \mathrm{month}^{-1}$ relative to PRS over the continent (Fig. 2h). SAI reduces precipitation with reference to RCP8.5. It reverses the RCP8.5 wetting in the tropics, where it reduces precipitation by more than $20 \mathrm{~mm} \mathrm{month}^{-1}$ (relative to RCP8.5), with the maximum decrease (>40 mm month ${ }^{-1}$, relative to RCP8.5) occurring over eastern Africa (Fig. 21). With reference to PRS, SAI leads to a net precipitation decrease of about $10 \mathrm{~mm} \mathrm{month}^{-1}$ over most parts of sub-Saharan Africa and a decrease of more than $20 \mathrm{~mm} \mathrm{month}^{-1}$ over eastern Africa (Fig. 2k). These results are consistent with the findings of Cheng et al. (2019). However, as the SAI intervention reverses the impacts of RCP8.5 on temperature, it induces a net CWB deficit over most parts of Africa (relative to PRS; Fig. 2o) because it decreases precipitation more than it decreases PET (cp. Figure 21 and k). The maximum CWB deficit is projected over eastern Africa (Fig. 2p). Hence, while the SAI intervention may reduce the CWB deficit over South Africa, it may impose a CWB deficit over east African countries, where a surplus CWB is projected without this intervention (Fig. 2p). Results of previous SAI studies suggest that the CWB deficit in the tropics can be avoided by using a moderate amount of SAI, which would only offset the impact 

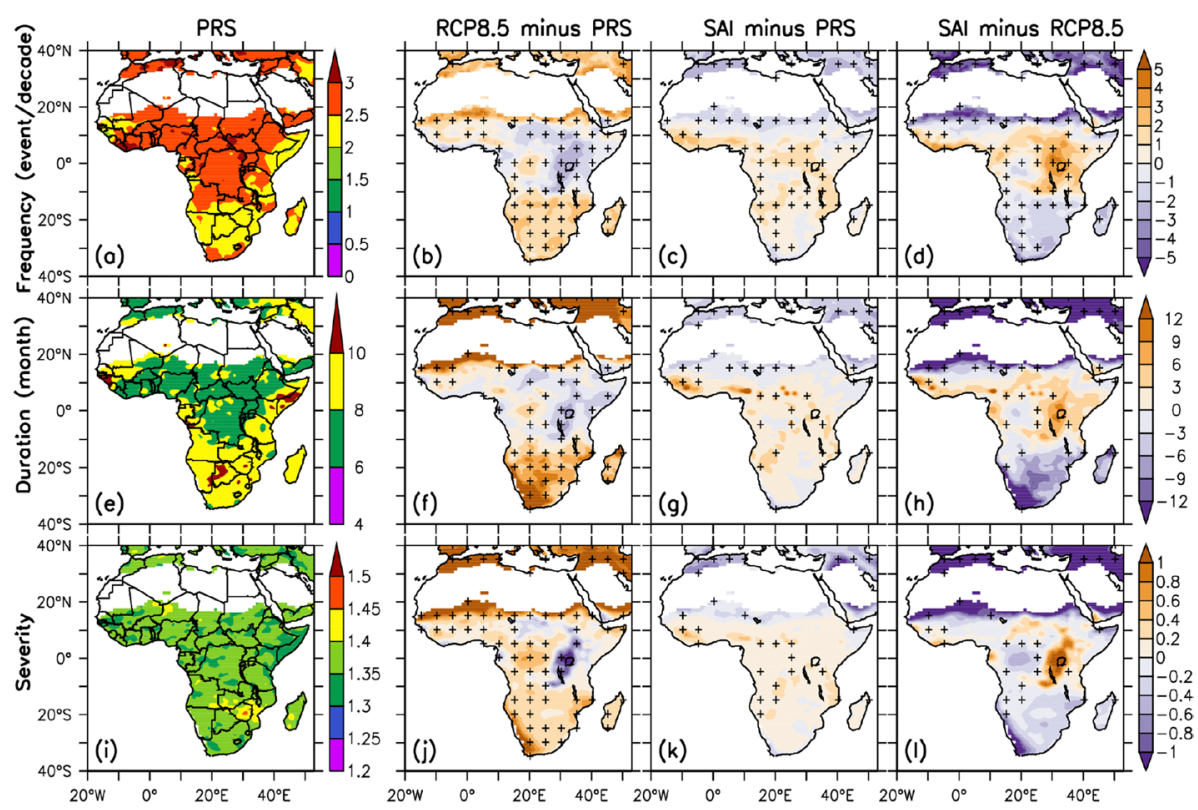

Fig. 3 Same as Fig. 2, but for SPEI drought characteristics (frequency, duration, and severity)

of RCP8.5 on precipitation. However, this would result in a higher residual of warming, which may be up to $1.75^{\circ} \mathrm{C}$ (Ferraro et al. 2014; MacMartin et al. 2019, Irvine and Keith 2020).

\subsection{Projected changes in drought characteristics over Africa}

The impacts of RCP8.5 on droughts over Africa depend on the drought indices (SPEI or SPI) used for the projection (Figs. 3 and 4). With the RCP8.5, the SPEI drought characteristics (frequency, duration, and severity) are projected to decrease over eastern Africa, but to increase elsewhere over the continent, with the maximum increase over southern Africa (south of $10^{\circ} \mathrm{S}$ ) (Fig. 3b, f, and j). In contrast, a decrease in SPI drought characteristics is projected over the whole of tropical Africa (except over the DRC) and over some parts of South Africa (Fig. 4b, f, and j). While a decrease in drought frequency is projected over eastern Africa, the magnitude of the decrease is higher for SPI ( $>5$ drought events decade ${ }^{-1}$ ) than for SPEI $\left(<5\right.$ drought events decade $\left.{ }^{-1}\right)$. Additionally, with reference to PRS, while an increase in drought duration is indicated for both indices over southern Africa, the magnitude of the increase is more pronounced for SPEI ( $>3$ months) than for SPI ( $<3$ months). The SPEI and CWB are driven by precipitation and evapotranspiration, and SPI is driven by precipitation (Fig. 3). These results are consistent with previous studies (e.g. Abiodun et al. 2018; Nguvava et al. 2019), which associated the difference between the two projections with the increase in atmospheric evaporative demand due to RCP8.5 warming.

The impacts of the SAI intervention on droughts also depend on the drought indices used. With SPEI, in reference to RCP8.5, the SAI increases the drought characteristics (frequency, duration, and intensity) over the entire tropical African region (except over 

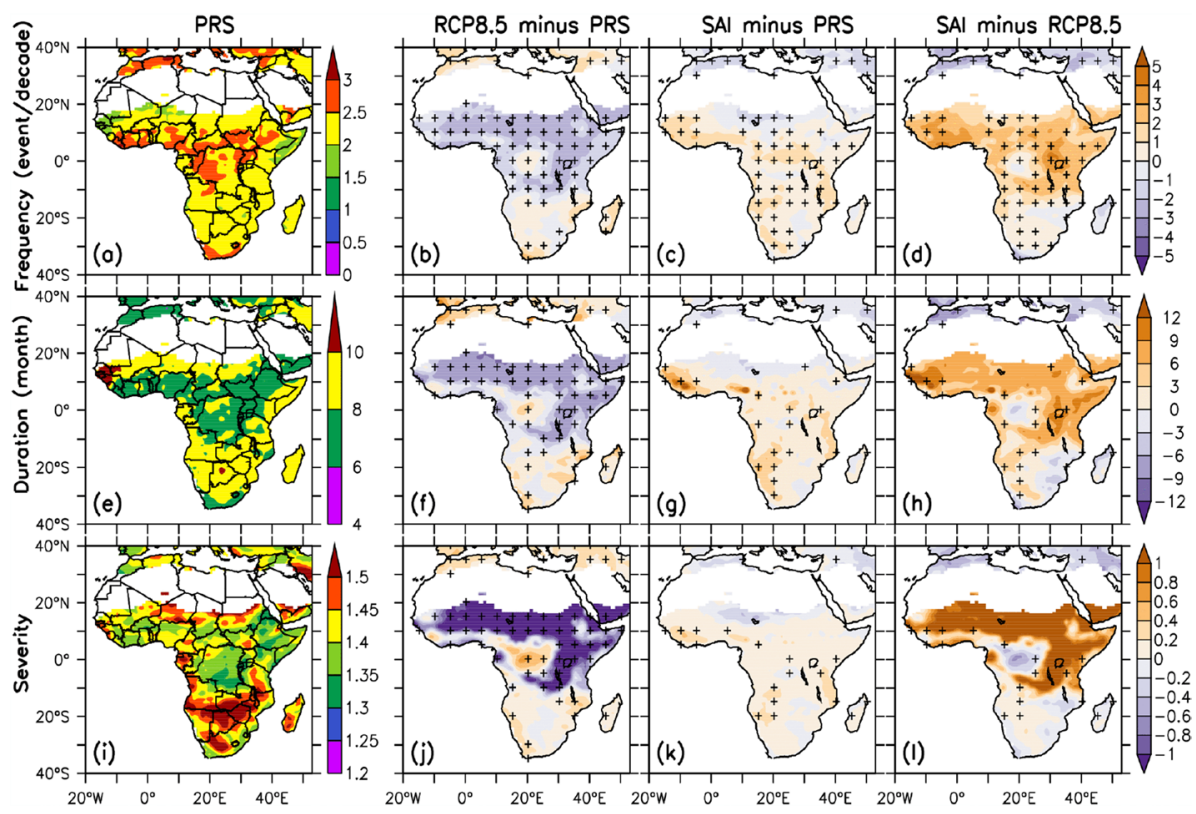

Fig. 4 Same as Fig. 2, but for SPI drought characteristics (frequency, duration, and severity)

Congo) (Fig. 3d, h, and 1) but lowers them over sub-tropical regions. Conversely, with SPI, the SAI increases the drought characteristics over most parts of the continent (except over Congo, along the southeastern coast of South Africa, and over southwestern South Africa). Although the SAI enhances both SPEI and SPI droughts over the tropics, the magnitude of this enhancement is higher for SPI droughts than for SPEI droughts. Nevertheless, in reference to PRS, both SPEI and SPI projections agree that the SAI intervention would lead to a net increase in drought characteristics over most parts of the continent, including over eastern Africa, where a decrease in drought characteristics is projected without the SAI intervention. These changes are consistent with the impacts of SAI on precipitation and CWB projection (Fig. 2). These results are based on a scenario where SAI offsets all the change in global mean temperature relative to the baseline 2020 conditions. If less SAI were used, the impacts of SAI intervention on the drought indices could be proportionally reduced.

\subsection{Projected changes in drought characteristics over the major river basin}

Figure 5 compares the impacts of RCP8.5 and the SAI intervention on SPEI and SPI droughts over the selected river basins. With RCP8.5, some basins feature an increase in both SPEI and SPI droughts, while some feature an increase in SPEI drought with a decrease in SPI droughts (Fig. 5a, d, and g). Only one basin (i.e. the Volta basin) features a decrease in both SPEI and SPI droughts. Regardless of the direction of the changes, all the basins show a gap between the SPEI and SPI projections, with the SPEI projection indicating more droughts than the SPI projection. The size of the gap, which indicates the extent to which the increase in PET could alter future droughts, varies over the basins. While the gap is relatively small over some basins (e.g. the Nile and Zambezi basins), it is relatively very large over some basins (i.e. the Chad and 

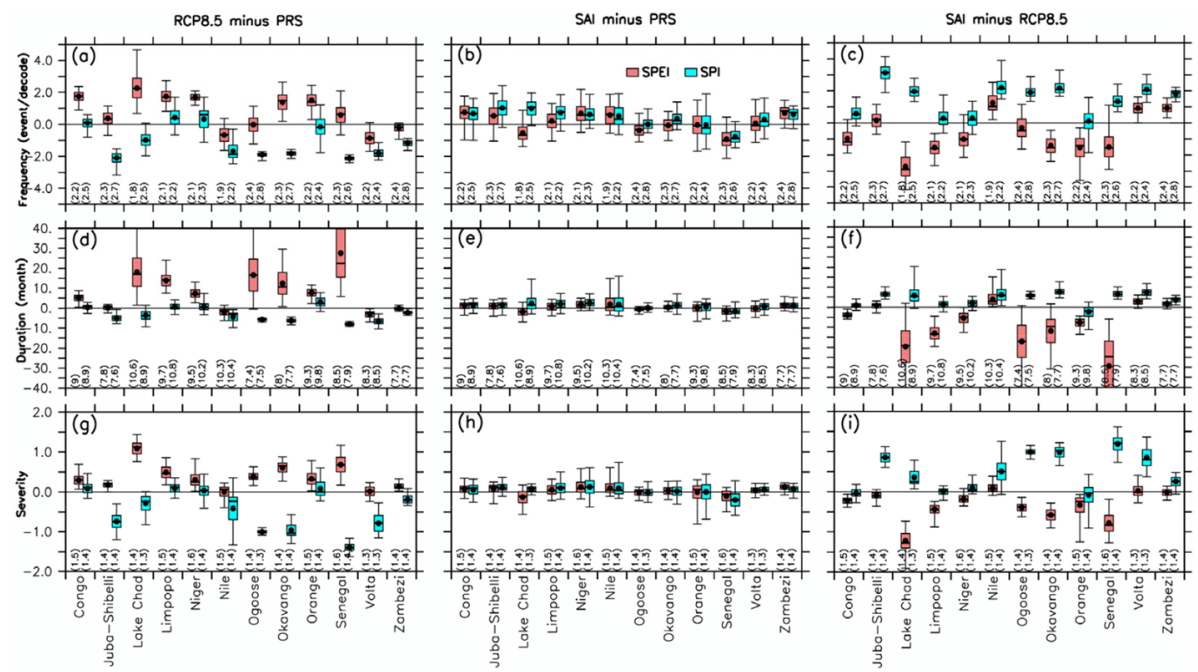

Fig. 5 Projected changes in characteristics of SPI and SPEI moderate droughts (i.e. frequency, duration, and severity) over the major river basins in Africa in the period (2071-2090) under the RCP8.5 climate scenario with reference to the present-day climate (2011-2030). The first column (RCP8.5-PRS) shows the future projections without the SAI intervention, while the second column (SAI-PRS) shows the future projections with the SAI intervention. The third column (SAI-RCP8.5) shows the impacts of the SAI intervention on the RCP8.5 warming. The lines of the boxplot show the ensemble spread (minimum, 1st quarter, median, 3rd quarter, and maximum), while the dot on the boxplot indicates the ensemble mean

Senegal basins), where the simulations suggest that the enhanced PET would drive the basin towards desertification ( $>25$ months drought duration per decade). These results are consistent with the findings of previous studies (e.g. Abiodun et al. 2018; Naik and Abiodun 2020; Nguvava et al. 2019; Ogutunde et al. 2020), which used multi-model simulations to project future drought characteristics over various basins in Africa.

The SAI intervention narrows the gaps between the SPEI and SPI projections over all the basins by either reducing the SPEI drought or increasing the SPI drought or doing both (Fig. 5). For example, while it reduces the gap over the Limpopo River basin (Fig. 5b, e, and h) by decreasing the SPEI drought (Fig. 5c, f, and i), it reduces the gap over the Juba-Shibelli basin, mainly by increasing the severity of the SPI drought. However, over most river basins, the gap is narrowed by a simultaneous decrease in SPEI and increase in SPI drought (Fig. 5c, f, and i). The maximum decrease in SPEI drought frequency ( $>2$ events decade ${ }^{-1}$ ) occurs over the Chad, Okavango, and Senegal basins, while the maximum increase in SPI droughts occurs over the Juba-Shibelli ( $>3$ events decade ${ }^{-1}$ ). It is only the Orange River basin that experiences a reduction in the gap through a decrease in both SPEI and SPI droughts. Note the differences in the drought results among the basins are not due to the differences in the characteristics of the basins. They are due to spatial variation in the impacts of climate change and the SAI intervention on the drought characteristics over the continent (Fig. 4), because the drought indices are obtained solely from atmospheric variables (i.e. precipitation, minimum temperature, and maximum temperature). 


\subsection{Implications for drought managements in the basins}

The reduction in the gap between SPEI and SPI drought projections over a basin has significant implications for the management of droughts in the basin. We illustrate this with a schematic diagram in Fig. 6, which depicts a case where SAI reduces the gap over a basin by decreasing the SPEI drought frequency projection (from 4.3 events decade $^{-1}$ to 3.1 events decade ${ }^{-1}$ ) and increasing the SPI drought frequency projection (from 1.7 events decade ${ }^{-1}$ to 2.9 events decade ${ }^{-1}$ ). This reduction lowers the level of uncertainty relating to future changes in drought frequency over the basin, because the SPI projection (which assumes no evapotranspiration) gives the lower limit of the change, while the SPEI projection (with potential or reference evapotranspiration) shows the upper limit of the change. However, while the reduction in the SPEI projection alleviates the risk of having an increase in the drought frequency of more than 4 events decade ${ }^{-1}$, the increase in the SPI projection removes the possibility of having an increase in the drought frequency of less than 2 events decade ${ }^{-1}$. Without the SAI intervention, the drought management practices have an opportunity to limit the increase in drought frequency to less than 2 events decade ${ }^{-1}$ by using various mitigations strategies (discussed in Abiodun et al. 2018; Naik and Abiodun 2019; Nguvava et al. 2019) to minimize evapotranspiration from the basin, especially over water-limiting basins, where evapotranspiration depends more on precipitation than on atmospheric water demand. But, with the SAI intervention, this opportunity is gone. The basin management is stuck with a future increase of more than 2.5 events decade $^{-1}$ in the drought frequency because of

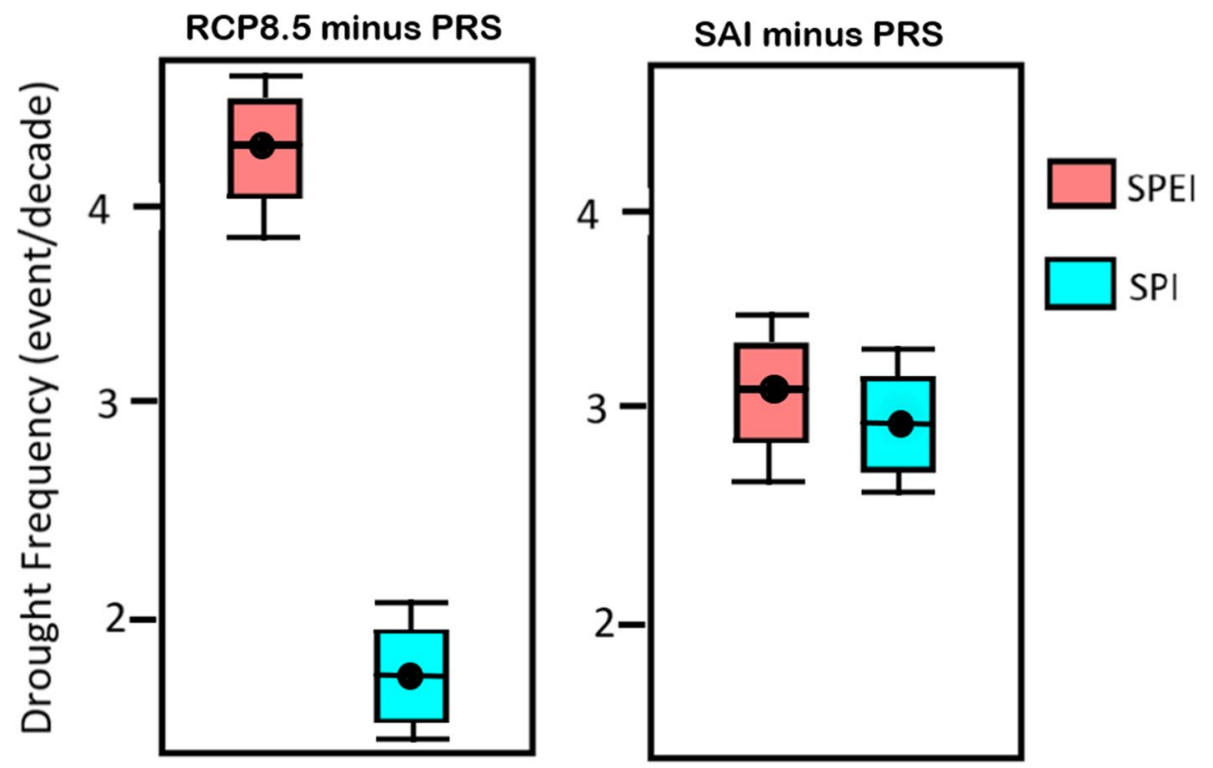

Fig. 6 A schematic illustration of the reduction in the SPEI and SPI drought projections over a river basin due to the SAI intervention. The first column (RCP8.5 minus PRS) shows the future projections without the SAI intervention, while the second column (SAI minus PRS) shows the future projections with the SAI intervention 
the reduced rainfall caused by SAI. Hence, the SAI intervention may have both positive and negative implications for drought management over the basin.

\section{Conclusion}

This study has investigated the extent to which the SAI intervention can mitigate the impacts of RCP8.5 warming on drought characteristics over Africa, by focusing on the 12 biggest and most transboundary river basins that support a wide range of socio-economic activities across the continent. Two climate simulation datasets from the GLENS Project (i.e. control and feedback) were analysed for the study. The control dataset was used to examine the impacts of climate change, while the two datasets were compared to examine the impacts of the SAI intervention. Two drought indices (SPI and SPEI) were employed in identifying and characterizing droughts over the study domain. Since SPI uses only precipitation to define drought, whereas SPEI uses both precipitation and PET to define drought, the gap between the SPEI and SPI projections was used to illustrate the impacts of enhanced atmospheric evaporative demand (due to RCP8.5 warming) on the drought projections. It was also used to indicate the range of uncertainty relating to future projections of drought and to indicate a window of opportunity to mitigate drought risk over the basin. The results of the study can be summarized as follows:

- The RCP8.5 warming increases temperature and atmospheric evaporative demand over Africa, and the magnitude of this increase is higher in the tropics than in the subtropics. The SAI intervention offsets this increase and keeps the temperature change within $\pm 0.5^{\circ} \mathrm{C}$ and the PET change within $\pm 5 \mathrm{~mm} \mathrm{month}^{-1}$.

- The RCP8.5 warming increases precipitation and induces a net CWB surplus in the tropics, and it decreases precipitation and produces a net CWB deficit in the sub-tropics. The SAI intervention overcompensates for these impacts, especially in the tropics, where it imposes a net CWB deficit.

- The enhancement in atmospheric evaporative demand by the RCP8.5 warming introduces a gap between the SPEI and SPI drought projections, but the size of this gap varies over the basins; it is largest over the Senegal basin and smallest over the Zambezi basin.

- The SAI intervention reduces the gap between SPEI and SPI drought projections over the basin by decreasing the SPEI droughts (through a reduced temperature and therefore lower atmospheric demand) and by increasing the SPI droughts (through reduced rainfall). The highest decrease in SPEI drought (frequency) occurs over the Senegal and Lake Chad basins, while the highest increase occurs over the Juba-Shibelli basin.

- The way in which the SAI intervention reduces the gap has serious implications for future management of droughts over the basins. While it reduces uncertainty relating to the drought, it also increases the lower limit of the drought projections and reduces the opportunity to mitigate the drought risk.

To obtain more robust information for policy making, the results of this study can be improved in different ways. Using hydrological models to downscale the results to river basin scales would provide more valuable information on the potential impacts of SAI intervention on streamflow, soil moisture, groundwater, and the associated hydrological droughts. The results of this study are based on GLENS, which employed a single model, 
single scenario, and single SAI strategy. Further studies could use more datasets from other SAI simulations (e.g. the Geoengineering Model Intercomparison Project, GeoMIP) and consider the influence of different SAI designs on the results. Nonetheless, there is reason to expect the broad conclusions may be somewhat robust, both with regard to the choice of climate model and the strategy employed, since the gap between SPEI and SPI results from a reduction in evaporative demand (which is a consequence of reduced temperatures), and this will remain true for any SAI simulation. The reduction in precipitation over much of Africa seen in GLENS may be different in different simulations; it is still present to some extent for different SAI strategies in the same model (e.g. Kravitz et al. 2016; Lee et al. 2020). Different models participating in GeoMIP show different regional patterns over Africa, but all show some subtropical precipitation reduction (Visioni et al. 2021).

Hausfather and Peters (2020) argued that the RCP8.5 scenario used in the study may be more of a 'worst-case' scenario rather than the 'business-as-usual' scenario. Since SRM is meant to avoid high levels of global warming (i.e. serious overshoot of $2.0^{\circ} \mathrm{C}$ ), the GLENS experiments targeted the RCP85 scenario, which is the scenario where SRM might be most seriously considered. However, we used this scenario because it is the only scenario available in the GLENS datasets. To explore the robustness of the results under more plausible scenarios (e.g. SSP2-4.5, SSP4-6.0, and SSP3-7.0; Hausfather and Peters 2020), future studies would use other datasets with various climate scenarios. Nonetheless, while the signal is higher under the high-emissions case, it is reasonable to expect the pattern of changes would be similar in a lower-emission scenario, with the magnitude of changes roughly proportional to the amount of warming being offset by SAI (see, e.g. MacMartin et al. 2019).

Acknowledgements We acknowledge the financial support of the DECIMALS fund of the Solar Radiation Management Governance Initiative, which was set up in 2010 by the Royal Society, Environmental Defense Fund and The World Academy of Sciences (TWAS) and is funded by the Open Philanthropy Project. The first author is also supported by the Water Research Commission (WRC, South Africa). The data used in this study are available to the community via the Earth System Grid (see information at www.cesm.ucar. edu/projects/community-projects/GLENS/). The CESM project is supported primarily by the National Science Foundation. The Centre for High Performance Computing (CHPC, South Africa) provided the computing facility used for the study. We thank the reviewers and the editor for their constructive comments, which strengthened the paper.

Open Access This article is licensed under a Creative Commons Attribution 4.0 International License, which permits use, sharing, adaptation, distribution and reproduction in any medium or format, as long as you give appropriate credit to the original author(s) and the source, provide a link to the Creative Commons licence, and indicate if changes were made. The images or other third party material in this article are included in the article's Creative Commons licence, unless indicated otherwise in a credit line to the material. If material is not included in the article's Creative Commons licence and your intended use is not permitted by statutory regulation or exceeds the permitted use, you will need to obtain permission directly from the copyright holder. To view a copy of this licence, visit http://creativecommons.org/licenses/by/4.0/.

\section{References}

Abatan AA, Gutowski WJ Jr, Ammann CM, Kaatz L, Brown BG, Buja L, Gotway JH (2017) Multiyear droughts and pluvials over the upper Colorado River basin and associated circulations. J Hydrometeorol 18(3):799-818

Abatan AA, Gutowski WJ Jr, Ammann CM, Kaatz L, Brown BG, Buja L, Bullock R, Fowler T, Gilleland E, Halley Gotway J (2018) Statistics of multi-year droughts from the method for object-based diagnostic evaluation. Int J Climatol 38(8):3405-3420 
Abiodun BJ, Makhanya N, Petja B, Abatan AA, Oguntunde PG (2019) Future projection of droughts over major river basins in Southern Africa at specific global warming levels. Theor Appl Climatol 137:1785-1799. https://doi.org/10.1007/s00704-018-2693-0

ARBO (Africa's River Basin Organization) (2007). Source book on Africa's River Basin Organization. Vol. 1. Available at: https://www.rioc.org/sites/default/files/IMG/pdf/AWRB_Source_Book.pdf. Accessed 01 Jun 2021

Beguería S, Vicente-Serrano SM, Reig F, Latorre B (2014) Standardized precipitation evapotranspiration index (SPEI) revisited: parameter fitting, evapotranspiration models, tools, datasets and drought monitoring. Int J Climatol 34(10):3001-3023

Bellprat O, Lott FC, Gulizia C, Parker HR, Pampuch LA, Pinto I et al (2015) Unusual past dry and wet rainy seasons over Southern Africa and South America from a climate perspective. Weather Clim Extrem 9:36-46. https://doi.org/10.1016/J.WACE.2015.07.001

Caldeira, K. and Wood, L. (2008). Global and Arctic climate engineering: numerical model studies. Phil Trans R Soc A 3664039-4056. https://doi.org/10.1098/rsta.2008.0132

Calow RC, MacDonald AM, Nicol AL, Robins NS (2010) Ground water security and drought in Africa: linking availability, access, and demand. Groundwater 48(2):246-256

Cheng, W., MacMartin, D.G., Dagon, K., Kravitz, B., Tilmes, S., Richter, J.H., Mills, M.J., and Simpson, I.R. (2019). Soil moisture and other hydrological changes in a stratospheric aerosol geoengineering large ensemble. Journal of Geophysical Research: Atmospheres. Blackwell Publishing Ltd, 124(23): 12773-12793. https://doi.org/10.1029/2018JD030237

Clay E, Borton J, Dhiri S. Gonzalez ADS, Pandolfi C (1995). Evaluation of ODA's response to the 199192 Southern Africa drought. Evaluation Report EV568. London. London, Overseas Development Administration.

Cook BI, Mankin JS, Marvel K, Williams AP, Smerdon JE, Anchukaitis KJ (2020) Twenty-first century drought projections in the CMIP6 forcing scenarios. Earth's Future 8:e2019EF001461

Da-Allada CY, Baloïtcha E, Alamou EA, Awo FM, Bonou F, Pomalegni Y et al (2020) Changes in West African summer monsoon precipitation under stratospheric aerosol geoengineering. Earth's Future 8:e2020EF001595. https://doi.org/10.1029/2020EF001595

Derrick J (1977) The great west African drought, 1972-1974. Afr Aff 76(305):537-586

Dosio, A., Jones, R.G., Jack, C., Lennard, C., Nikulin, G., and Hewitson, B. (2019). What can we know about future precipitation in Africa? Robustness, significance and added value of projections from a large ensemble of regional climate models Clim Dyn. https://doi.org/10.1007/s00382-019-04900-3

Feddema JJ (1999) Future African water resources: interactions between soil degradation and global warming. Clim Change 42(3):561-596

Feng H, Zhang M (2015) Global land moisture trends: drier in dry and wetter in wet over land. Sci Rep 5:18018. https://doi.org/10.1038/srep18018

Ferraro AJ, Highwood EJ, Charlton-Perez AJ (2014) Weakened tropical circulation and reduced precipitation in response to geoengineering. Environ Res Lett 9:014001. https://doi.org/10.1088/1748-9326/9/ $1 / 01400$

Funk, C., Harrison, L., Shukla, S., Pomposi, C., Galu, G., Korecha, D., et al. (2018). Examining the role of unusually warm Indo-Pacific sea surface temperatures in recent African droughts Q J R Meteorol Soc. https://doi.org/10.1002/acr

Guha-Sapir D, Hargitt D, Hoyois P (2004) Thirty years of natural disasters 1974-2003: The numbers. Presses Universitaires de Louvain, Louvain

Hargreaves GL, Samani ZA (1985) Reference crop evapotranspiration from temperature. Appl Eng Agric 1:96-99

Hausfather Z, Peters G (2020) Emissions-The 'business as usual' story is misleading. Nature 577:618-620

Hayes M, Svoboda M, Wall N, Widhalm M (2011) The Lincoln declaration on drought indices: universal meteorological drought index recommended. Bull Am Meteorol Soc 92:485-488

Hegerl, G.C., Crowley, T.J., Baum, S.K., Kim, K.Y. and Hyde, W.T. (2003). Detection of volcanic, solar and greenhouse gas signals in paleo-reconstructions of Northern Hemispheric temperature. Geophys Res Lett 30(5)

Hope KR Sr (2009) Climate change and poverty in Africa. Int J Sust Dev World 16(6):451-461

Irvine PJ, Keith DW (2020) Halving warming with stratospheric aerosol geoengineering moderates policyrelevant climate hazards. Environ Res Lett 15(4):044011

James R, Washington R (2013) Changes in African temperature and precipitation associated with degrees of global warming. Clim Change 117(4):859-872

Jones A, Haywood J, Boucher O, Kravitz B, Robock A (2010) Geoengineering by stratospheric SO2 injection: results from the Met Office HadGEM2 climate model and comparison with the Goddard 
Institute for Space Studies ModelE. Atmos Chem Phys 10(5999-6006):2010. https://doi.org/10.5194/ acp-10-5999-2010

Joshi M, Hawkins E, Sutton R, Lowe J, Frame D (2011) Projections of when temperature change will exceed $2^{\circ} \mathrm{C}$ above pre-industrial levels. Nat Clim Chang 1(8):407-412

Kravitz B, MacMartin DG, Wang H, Rasch PJ (2016) Geoengineering as a design problem. Earth Syst Dyn 7(2):469-497. https://doi.org/10.5194/esd-7-469-2016

Kugbega SK, Aboagye PY (2021) Farmer-herder conflicts, tenure insecurity and farmer's investment decisions in Agogo, Ghana. Agricultural and Food Economics 9(1):1-38

Lee W, MacMartin D, Visioni D, Kravitz B (2020) Expanding the design space of stratospheric aerosol geoengineering to include precipitation-based objectives and explore trade-offs. Earth Syst Dyn 11(4):1051-1072

Lian X, Piao S, Chen A, Huntingford C, Fu B, Li LZ, Huang J, Sheffield J, Berg AM, Keenan TF, McVicar TR (2021) Multifaceted characteristics of dryland aridity changes in a warming world. Nat Rev Earth Environ 2(4):232-250

Liu C, Allan RP (2013) Observed and simulated precipitation responses in wet and dry regions 1850-2100. Environ Res Lett 8:034002. https://doi.org/10.1088/1748-9326/8/3/034002

MacMartin DG, Wang W, Kravitz B, Tilmes S, Richter JH, Mills MJ (2019) Timescale for detecting the climate response to stratospheric aerosol geoengineering. J Geophys Res Atmos 124:1233-1247. https:// doi.org/10.1029/2018JD028906

Mahlalela PT, Blamey RC, Reason CJC (2019) Mechanisms behind early winter rainfall variability in the southwestern Cape, South Africa. Clim Dyn 53:21-39. https://doi.org/10.1007/s00382-018-4571-y

Masih I, Maskey S, Mussá FEF, Trambauer P (2014) A review of droughts on the African continent: a geospatial and long-term perspective. Hydrol Earth Syst Sci 18(9):3635-3649

Masike S, Urich PB (2009) The projected cost of climate change to livestock water supply and implications in Kgatleng District, Botswana. World J Agric Sci 5(5):597-603

Maúre G, Pinto I, Ndebele-Murisa M, Muthige M, Lennard C, Nikulin G, Meque A (2018) The southern African climate under $1.5 \mathrm{C}$ and $2 \mathrm{C}$ of global warming as simulated by CORDEX regional climate models. Environ Res Lett 13(6):065002

McKee TB, Doesken NJ, Kleist J (1993) The relationship of drought frequency and duration to time scale. Preprints, Eighth Conference on Applied Climatology, Anaheim, CA, Amer. Meteor. Soc., 179-184

Meque A, Abiodun BJ (2015) Simulating the link between ENSO and summer drought in Southern Africa using regional climate models. Clim Dyn 44(7):1881-1900

Mills MJ, Richter JH, Tilmes S, Kravitz B, MacMartin DG, Glanville AA, Tribbia JJ, Lamarque JF, Vitt F, Schmidt A, Gettelman A (2017) Radiative and chemical response to interactive stratospheric sulfate aerosols in fully coupled CESM1 (WACCM). J Geophys Res Atmos 122(23):13-061

Naik M, Abiodun BJ (2020) Projected changes in drought characteristics over the Western Cape, South Africa. Meteorol Appl 27(1):e1802

National Academies of Sciences, Engineering, and Medicine. 2021. Reflecting sunlight: recommendations for solar geoengineering research and research governance. Washington, DC: The National Academies Press. https://doi.org/10.17226/25762

Nguvava M, Abiodun BJ, Otieno F (2019) Projecting drought characteristics over East African basins at specific global warming levels. Atmos Res 228:41-54

Odoulami RC, Wolski P, New M (2021) A SOM-based analysis of the drivers of the 2015-2017 Western Cape drought in South Africa. Int J Climatol 41:E1518-E1530

Oguntunde PG, Abiodun BJ, Lischeid G, Abatan AA (2020) Droughts projection over the Niger and Volta River basins of West Africa at specific global warming levels. Int J Climatol 40(13):5688-5699

Omar SA, Abiodun BJ (2020) Characteristics of cut-off lows during the 2015-2017 drought in the Western Cape, South Africa. Atmos Res 235:104772

Onyutha C (2021) Trends and variability of temperature and evaporation over the African continent: relationships with precipitation. Atmósfera 34(3):267-287

Otto FEL, Wolski P, Lehner F, Tebaldi C, van Oldenborgh GJ, Hogesteeger S, Singh R, Holden P, Fučkar NS, Odoulami RC, New M (2018) Anthropogenic influence on the drivers of the Western Cape drought 2015-2017. Environ Res Lett 13(12):124010. https://doi.org/10.1088/1748-9326/aae9f9

Padrón RS, Gudmundsson L, Decharme B, Ducharne A, Lawrence DM, Mao J et al (2020) Observed changes in dry-season water availability attributed to human-induced climate change. Nat Geosci 13:477-481. https://doi.org/10.1038/s41561-020-0594-1

Palmer WC (1965) Meteorological drought, Weather Bureau, 30. US Department of Commerce, Washington, DC, pp 1-59 
Pascale S, Kapnick SB, Delworth TL, Cooke WF (2020) Increasing risk of another Cape Town "Day Zero" drought in the 21st century. Proc Natl Acad Sci 117:29495 LP - 29503. https://doi.org/10.1073/pnas. 2009144117

Pinto, I., Jack, C., Lennard, C., Tilmes, S., and Odoulami, R.C. (2020). Africa's climate response to solar radiation management with stratospheric aerosol. Geophys Res Lett 47(2) https://doi.org/10.1029/ 2019GL086047

Proctor J, Hsiang S, Burney J, Burke M, Schlenker W (2018) Estimating global agricultural effects of geoengineering using volcanic eruptions. Nature 560(7719):480-483. https://doi.org/10.1038/ s41586-018-0417-3

Ricke K, Morgan M, Allen M (2010) Regional climate response to solar-radiation management. Nature Geosci 3:537-541. https://doi.org/10.1038/ngeo915

Robock A 2015 Stratospheric aerosol geoengineering AIP Conf Proc 1652:183-97

Serdeczny O, Adams S, Baarsch F, Coumou D, Robinson A, Hare W, Schaeffer M, Perrette M, Reinhardt J (2017) Climate change impacts in Sub-Saharan Africa: from physical changes to their social repercussions. Reg Environ Change 17(6):1585-1600

Shiferaw B, Tesfaye K, Kassie M, Abate T, Prasanna BM, Menkir A (2014) Managing vulnerability to drought and enhancing livelihood resilience in sub-Saharan Africa: technological, institutional and policy options. Weather Clim Extremes 3:67-79

Simpson IR, Tilmes S, Richter JH, Kravitz B, MacMartin DG, Mills MJ, Fasullo JT, Pendergrass AG (2019) The regional hydroclimate response to stratospheric sulfate geoengineering and the role of stratospheric heating. J Geophys Res Atmos 124(23):12587-12616. https://doi.org/10.1029/2019JD031093

Sousa PM, Blamey RC, Reason CJC, Ramos AM, Trigo RM (2018) The 'Day Zero' Cape Town drought and the poleward migration of moisture corridors. Environ Res Lett 13:124025. https://doi.org/10. 1088/1748-9326/aaebc7

Spinoni J, Barbosa P, Bucchignani E, Cassano J, Cavazos T, Christensen JH et al (2020) Future global meteorological drought hot spots: a study based on CORDEX data. J Clim 33:3635-3661. https://doi.org/ 10.1175/JCLI-D-19-0084.1

Spinoni J, Barbosa P, De Jager A, McCormick N, Naumann G, Vogt JV et al (2019) A new global database of meteorological drought events from 1951 to 2016. J Hydrol Reg Stud 22:100593. https://doi.org/10. 1016/J.EJRH.2019.100593

Stenchikov GL, Kirchner I, Robock A, Graf H-F, Antuna JC, Grainger RG, Lambert A, Thomason L (1998) Radiative Forcing from the 1991 Mount Pinatubo volcanic eruption. J Geophys Res 103(D12):13837-13857

Svoboda MD, Fuchs BA (2016) Handbook of drought indicators and indices. World Meteorological Organization, Geneva, pp 1-44

Tilmes S, Richter JH, Kravitz B, MacMartin DG, Mills MJ, Simpson IR, Glanville AS, Fasullo JT, Phillips AS, Lamarque J-F, Tribbia J, Edwards J, Mickelson S, Ghosh S (2018) CESM1(WACCM) stratospheric aerosol geoengineering large ensemble project. Bull Am Meteor Soc 99(11):2361-2371. https://doi.org/10.1175/BAMS-D-17-0267.1

Trenberth KE, Dai A, Van Der Schrier G, Jones PD, Barichivich J, Briffa KR, Sheffield J (2014) Global warming and changes in drought. Nature Climate Change 4(1):17-22

Uhe P, Sjoukje P, Sarah K, Kasturi S, Joyce K, Emmah M et al (2017) Attributing drivers of the 2016 Kenyan drought. Int J Climatol 38:e554-e568. https://doi.org/10.1002/joc.5389

Verissimo COJ (2020) Ethics of superpowers and civil wars in Africa. The Palgrave Handbook of African Social Ethics. Palgrave Macmillan, Cham, pp 203-216

Vicente-Serrano SM, Beguería S, López-Moreno JI (2010a) A multiscalar drought index sensitive to global warming: the standardized precipitation evapotranspiration index. J Clim 23(7):1696-1718. https://doi. org/10.1175/2009JCLI2909.1

Vicente-Serrano SM, Beguería S, López-Moreno JI, Angulo M, El Kenawy A (2010) A new global $0.5^{\circ}$ gridded dataset (1901-2006) of a multiscalar drought index: comparison with current drought index datasets based on the Palmer drought severity index. J Hydrometeorol 11(4):1033-1043. https://doi. org/10.1175/2010JHM1224.1

Visioni D, MacMartin DG, Kravitz B (2021) Is turning down the sun a good proxy for stratospheric sulfate geoengineering? J Geophys Res Atmos 126(5):e2020JD033952

Wolski P (2018) How severe is Cape Town's "Day Zero" drought? Significance 15:24-27. https://doi.org/ 10.1111/j.1740-9713.2018.01127.x

World Meteorological Organization (2012) Standardized precipitation index user guide In: Svoboda M, Hayes M,Wood D (WMO-No. 1090), Geneva 
Publisher's note Springer Nature remains neutral with regard to jurisdictional claims in published maps and institutional affiliations.

\section{Authors and Affiliations}

Babatunde J. Abiodun ${ }^{1}$ D $\cdot$ Romaric C. Odoulami ${ }^{2}$ (D) $\cdot$ Windmanagda Sawadogo ${ }^{3}$ (D) Olumuyiwa A. Oloniyo' ${ }^{1}$ Abayomi A. Abatan ${ }^{4}$ (D) Mark New ${ }^{2}$. Christopher Lennard ${ }^{1}$. Pinto Izidine $^{1} \cdot$ Temitope S. Egbebiyi ${ }^{1}$. Douglas G. MacMartin ${ }^{5}$

Romaric C. Odoulami

romaric.odoulami@uct.ac.za

Mark New

mark.new@uct.ac.za

1 Climate Systems Analysis Group, Department of Environmental and Geographical Science, University of Cape Town, Cape Town, South Africa

2 African Climate and Development Initiative, University of Cape Town, Cape Town, South Africa

3 Institute of Geography, University of Augsburg, Augsburg, Germany

4 College of Engineering, Mathematics and Physical Sciences, University of Exeter, Exeter, UK

5 Mechanical and Aerospace Engineering, Cornell University, Ithaca, NY, USA 